\section{3 \\ ANALYSIS OF COMPOSITE TUBE CRACKING IN RECOVERY BOILER FLOORS •}

\author{
J. R. Keiser, B. Taljat, X.-L. Wang, P. J. Maziasz, \\ C. R. Hubbard, and R. W. Swindeman \\ Oak Ridge National Laboratory \\ Oak Ridge, Tennessee \\ D. L. Singbeil and R. Prescott \\ Pulp and Paper Research Institute of Canada \\ Vancouver, British Columbia
}

\section{ABSTRACT}

Cracking of co-extruded (generally identified as composite) floor tubes in kraft black liquor recovery boilers was first observed in Scandinavia, but this problem has now been found in many North American boilers. In most cases, cracking in the outer 304L stainless steel has not progressed into the carbon steel, but the potential for such crack propagation is a cause of concern.

A multidimensional study has been initiated to characterize the cracking seen in composite floor tubes, to measure the residual stresses resulting from composite tube fabrication, and to predict the stresses in tubes under operating conditions. The characterization studies include review of available reports and documents on composite tube cracking, metallographic examination of a substantial number of cracked tubes, and evaluation of the dislocation structure in cracked tubes. Neutron and X-ray diffraction are being used to determine the residual stresses in composite tubes from two major manufacturers, and finite element analysis is being used to predict the stresses in the tubes during normal operation and under conditions where thermal fluctuations occur.

\section{INTRODUCTION}

Black liquor recovery boilers are a critical component in kraft pulp and paper mills, however, they constitute a major source of materials problems. Because of the ever-present potential for an explosion because of a smelt-water reaction, it is critical that the tube material used for the floor and lower walls have adequate corrosion resistance. Composite tubing of 304L stainless steel on carbon steel was adopted for use in black liquor recovery boilers in order to provide sufficient corrosion resistance at the higher

* Research sponsored by the U.S. Department of Energy, Assistant Secretary for Energy Efficiency and Renewable Energy, Office of Industrial Technologies, Advanced Industrial Materials Program, under contract DR-AC05-96OR22464 with Lockheed Martin Energy Research Corp.

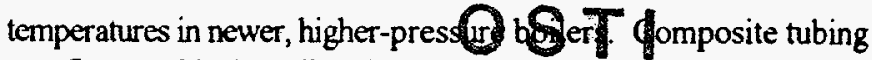
was first used in Scandinavia, and it was also in Scandinavia that cracking of the stainless steel was first observed (1). Before these cracking problems were reported, use of this tubing was adopted in North America. Subsequently, cracking problems were also noted in North American mills $(2,3)$.

An explanation for this cracking has been sought by paper companies, boiler manufacturers, tube fabricators, and researchers at a number of facilities. It has been attributed to a variety of causes including thermal fatigue, stress corrosion cracking, down. time corrosion, or a combination of these or other mechanisms. However, neither the cause of composite tube cracking nor an effective solution has yet been identified. Therefore a United States Department of Energy-funded program has been established to develop a more thorough understanding of the degradation in the composite tubing used for walls and floors. This program includes collection and review of technical reports, collection and analysis of smelt samples, collection and tabulation of temperature data, microstructural characterization of composite tubing, measurement of residual stresses in both as-produced and asformed composite tubing, computer modeling to predict stresses under operating conditions, and operation of laboratory fatigue and corrosion tests. The research is being carried out at the Oak Ridge National Laboratory (ORNL), the Pulp and Paper Research Institute of Canada (Paprican), and the Institute of Paper Science and Technology (IPST) with strong cooperation from many paper companies, most major manufacturers of recovery boilers, and one of the principal producers of composite tubing. From this work it is anticipated that methods or alternate materials will be identified that can prevent composite tube cracking. The purpose of this paper is to report on the status of this study.

At this time, a report summarizing information in the open literature and in restricted-distribution reports and documents is nearing completion. In a separate effort, a significant number of cracked composite tube samples has been examined, and some conclusions have been drawn. Although not discussed here, work has also been initiated to collect and analyze smelt samples and to compile temperature data from floor thermocouples in order to characterize the environments encountered by composite floor tubes.

Because of the significant difference in the thermal expansion coefficients of SA210 Grade A1 carbon steel and type 304L stainless steel (4L7 and 3R12 for European tubing), there could be significant stresses developed in the tubing that might contribute to fatigue or stress corrosion cracking. In order to determine the nature and magnitude of these stresses, neutron and X-ray diffraction studies have been conducted on as-fabricated, unexposed composite tube samples. Results of room temperature measurements of residual stresses in composite tube samples from the two primary manufacturers of composite tubing for recovery boilers are also described.

-The submitted manuscript has been authored by a contractor "The submitted manuscript has been authored by a cont of the U.S. government under contract NO. DE-ACDS 96OR22464. Accordingly, the U.S. Government retains a nonexclusive, royalty-free license to publish or reproduce the published form of this contribution for U.S. Government purposes."

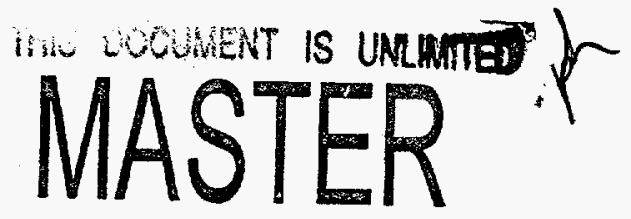




\section{DISCLAMMER}

This report was prepared as an account of work sponsored by an agency of the United States Government. Neither the United States Government nor any agency thereof, nor any of their employees, makes any warranty, express or implied, or assumes any legal liability or responsibility for the accuracy, completeness, or usefulness of any information, apparatus, product, or process disclosed, or represents that its use would not infringe privately owned rights. Reference herein to any specific commercial product, process, or service by trade name, trademark, manufacturer, or otherwise does not necessarily constitute or imply its endorsement, recommendation, or favoring by the United States Government or any agency thereof. The views and opinions of authors expressed herein do not necessarily state or reflect those of the United States Government or any agency thereof. 


\section{DISCLAIMER}

Portions of this document may be illegible in electronic image products. Images are produced from the best available original document. 
The results of the residual stress measurements have been used in a finite element model to predict the stresses that develop in the composite tubing at operating conditions as a result of tube fabrication, welding membranes to opposite positions on the composite tubes, pressurizing the tubing, and applying heat only to the fireside of the tubing. The results indicate that the fireside surfaces of 304L/SA210 composite tubes are under compressive stresses under normal operating conditions. As a result, a threedimensional model was developed to consider the effects of heating a small area on the tube panel surface to a higher than normal temperature.

\section{RESULTS}

\section{Literature Review}

The Pulp and Paper Research Institute of Canada has the lead role in publication of a state-of-the-art report on co-extruded or composite tubing used in kraft recovery boilers. Information sources that were consulted include tube manufacturers, boiler manufacturers, public domain literature, companies operating kraft recovery boilers, consultants, and university and failure analysis laboratories. In addition to obtaining written documentation from these sources, visits were made by members of the research team to manufacturing facilities for the tubes and boilers, mill sites during operation of the boilers and on shutdowns when the equipment was available for inspection, university laboratories and consultants' offices. An overview of information obtained to date from these sources is outlined below.

There are two principal manufacturers of composite tubes worldwide: Sandvik Steel $A B$ in Sweden and Sumitomo Metals in Japan. Other, smaller manufacturers also exist, but they sell very little material to the pulp and paper market. There are no North American fabricators of this type of tubing. The bulk of composite tubes sold in North America comes from the Japanese manufacturer, largely as a consequence of marketing agreements with the North American boiler manufacturers. The Swedish manufacturer does have a significant presence in North America, but sells most of its product in Europe.

Six boiler manufacturers compete for most of the worldwide recovery boiler sales. In North America, the principal suppliers are ABB Combustion Engineering and Babcock \& Wilcox. Kvaerner Pulping Technologies has its headquarters in Sweden while A. Ahlstrom Corporation and Tampella Power Corporation are based in Finland. Mitsubishi is a prominent Japanese boiler manufacturer. The European manufacturers were the earliest to adopt the use of composite tubes for wall and floor construction (1972 and 1978 respectively). The North American boiler manufacturers began use of composite tubes about five years later than their European counterparts. By 1983, cracks in composite tubes had been observed in spout opening tubes (1-3), and in floor tubes by 1986 (4). By 1992, cracks had also been reported in floor tubes installed in some North American boilers $(5,6)$.
Boiler design plays a role in the location and severity of cracking, but no design has proven immune to composite tube cracking. The time from installation to first cracking for floor tubes has been reported to vary from 4 to 48 months. Higher pressure boilers [8.27-10.34 MPa (1200-1500 psi) steam pressure] were the first to report cracks, but they are more often constructed with composite tubes. Many low pressure boilers 4.14-6.21 MPa (600. $900 \mathrm{psi}$ ) also have experienced cracked floor tubes. Initial reports in North America led to the mistaken belief that cracking was restricted to boiler designs with a sloped floor. This early report of incidences of cracked floor tubes was due in part to the greater ease with which sloped floor boilers are inspected and to the fact that the preponderance of composite floor tubes used in North America were supplied to sloped floor boilers. Reports of boilers with cracked tubes continue to increase as inspection techniques mature and information on the problem circulates among the operating companies.

Cracking of composite tubes has been commonly found at three locations within the lower furnace of recovery boilers. Floor tubes may present the most serious problem because cracking can affect large numbers of tubes over significant portions of their length. However, the greatest volume of information relates to cracking in the vicinity of the smelt spout openings. In addition, a number of incidents have been reported where cracking has taken place around the primary air ports. Cracks at spout openings and air ports are more easily detected than cracks in floor tubes simply because the former are easier to inspect. In order to detect cracks in the floor tubes, it is necessary to remove the ash, the burneddown char bed, and the solidified layer of smelt from the furnace floor.

In boilers with sloping floors, it appeared that floor tube cracking was mostly located within two meters of the wall containing the smelt spouts and that the cracked area often was centered in front of the spouts. In one boiler it was reported that the worst cracking was located just before the downward bend to the header. Cracking has also been detected in boilers with composite wall tubes that extend for a short distance into the floor before joining studded carbon steel floor tubes. In such boilers, cracks have also been noted at the butt welds between the composite tubing and the carbon steel tubes.

There are numerous records of cracking at spout openings dating from 1983 to the present. In most cases lifetime was less than four years and frequently it was less than a year. Some openings had to be changed after only four months, and in one case, cracks were detected within two months. Some of the reports drew attention to factors which may influence the cracking of spout openings. These included the effects of using metal rods (rodding) to knock solidified smelt out of openings thus exposing the tubes to sudden temperature changes and contact with liquid smelt. It was also suggested that smelt fluidity and fluctuating levels may be important (7). 
In North American boilers there are records of cracking at primary air ports dating back to 1983, and problems are still being encountered with the most recent report coming in the fall of 1995 . In most cases, cracked tubes have been detected after less than five years of service. In one boiler, cracking was noted after only nine months. However, the only reported incident of a water leak from a cracked composite tube took place at a primary air port opening in 1983. Failure analysis suggested that overheating had played a roll; but the cause was thought to be predominately thermal fatigue.

Failure reports typically attribute cracking in composite tubes to thermal fatigue, corrosion fatigue, or stress corrosion cracking. In some cases, principally around air ports and smelt spout openings where severe restraint from crotch plates and attachment welds is present, thermal fatigue appears to be a very likely mechanism. In other cases, principally in floor tubes, there is no compelling evidence to prove that one or the other of these mechanisms is predominant, notwithstanding the sometimes definitive conclusions reached by many of the reports examined.

Differentiating among failure mechanisms is difficult since very few tubes have been subjected to a complete metallographic failure analysis relative to the total number of cracked tubes identified in boilers. Most cracked tubes are returned to service or repaired in place rather than removed. With the exception of a few summary reports from Scandinavia (8-11), conclusions regarding the mechanism of cracking have, for the most part, been drawn from a detailed examination of only one or two tube specimens. This issue is of particular concern because only a detailed failure analysis can confirm whether or not cracks have propagated through the interface between the outer stainless steel layer and the inner carbon steel. There is currently a widespread belief that this is unlikely, despite the fact that several incidents of crack propagation through the interface have been documented. While most occurrences have been at spout openings where thermal fatigue is clearly a factor, two instances of cracking into the carbon steel have been documented by this project, and verbal reports (no confirming metallography) of two other cases have been received.

\section{Microstructural Characterization of Composite Tubing}

The microstructural studies which are being conducted at ORNL have several objectives. One is to document the microstructural features of unexposed, as-fabricated composite tubing both as a function of the material and the tube fabricator. Another objective is to characterize a significant number of samples from composite tubes after exposure in a recovery boiler. Exposed samples are generally taken from tubing that was removed from service because of cracking or other degradation. A third objective is to collect information that might help differentiate between environmentally assisted stress corrosion cracking and a fatigue mechanism as the cause of cracking on the composite tubes and the membranes.
Characterization of unexposed composite tubes. A number of unexposed tubing samples have been examined. Sandvik Steel provided samples of 3R12/4L7 (304L/SA210) and SAN 38/4L7 (modified 825/SA210) in both $21 / 2$ and 3 in. OD sizes and Babcock \& Wilcox provided samples of Sumitomo Metal's $2 \frac{1}{2}$ in. tubing in both 304LSA210 and Alloy 825/SA210. Samples of all six of these material/manufacturer/size combinations were examined to define the microstructure on the outer surface and along the stainless steel/carbon steel interface. The outer surfaces of the samples typically have some roughness and irregularities, but there are no significant microstructural features (grain size differences, carbide precipitation, etc)

The stainless steel/carbon steel interfaces on all of the samples showed a characteristic pattern with an 80-100 $\mu \mathrm{m}$ thick decarburized zone in the carbon steel adjacent to the stainless steel/carbon steel interface along with a region in the stainless steel adjacent to the interface containing a high concentration of procipitates. Micrographs of these two areas are shown in Fig. 1.

As part of the characterization, the hardness in the vicinity of the interface was also determined. The hardness measurements were made using both a $100 \mathrm{gm}$ load to determine the hardness over a wide area and a $10 \mathrm{gm}$ load to get a better indication of short range hardness variations since the hardness indentation covers a much smaller area and thus samples a smaller volume. The hardness measurements shown in Fig. 2 indicate a maximum occurs in the stainless steel immediately adjacent to the interface. With increasing distance into the stainless steel from the interface, the hardness decreased fairly rapidly. In the carbon steel near the interface, the hardness showed a minimum value in the area of the decarburized zone. Comparison of the results for all six samples show the results are qualitatively similar.

Measurement of carbon and nitrogen concentrations was done in the vicinity of the interface on one sample. The results show that nitrogen had essentially no variation across the interface, but carbon shows a significant increase in concentration adjacent to the interface in the austenitic alloy.

This hard, carbide-rich region in the stainless steel near the interface may have an influence on the path taken by cracks in the stainless steel (see the section in this paper on examination of exposed tubes). Modeling studies have predicted and controlled experiments have confirmed that fatigue cracks perpendicularly approaching an interface between a strong and a weak material will tend to be arrested before crossing the interface if the crack is advancing toward the stronger material (12). If, however, the crack is moving through the stronger material toward the plastically weaker material, the crack will tend to move unimpeded across the interface. The full relevance of this observation to crack propagation in composite materials is not clear because it assumes fatigue cracking and it assumes certain material properties that may not accurately describe the composite tubing. Nevertheless, 


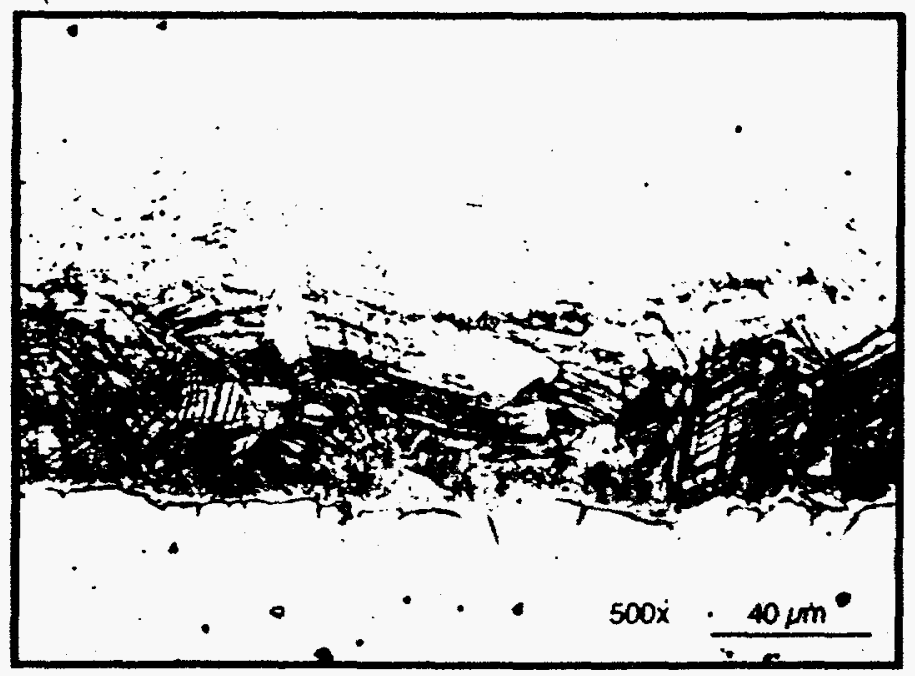

a)

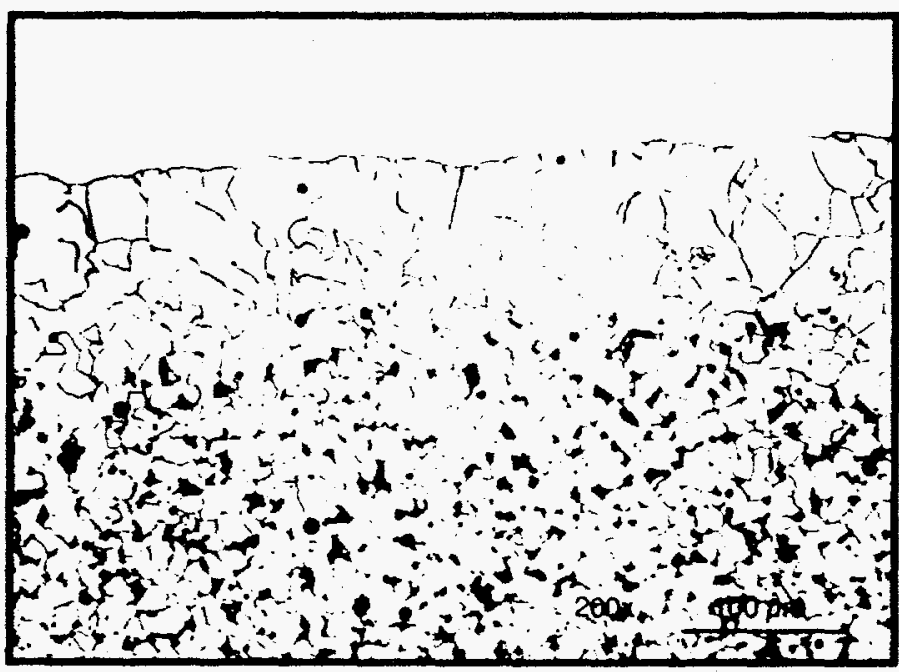

b)

Fig. 1. Micrographs of $304 \mathrm{~L} / \mathrm{SA} 210$ composite tube near the stainless steel/carbon steel interface showing a) carbide precipitates in stainless steel (aqua regia etch) and b) decarburized region in carbon steel ( $2 \%$ nital etch).

there is an indication the carbide-rich region along the interface can affect the progression of cracks in the composite tubing.

Examination of exposed composite tubes. An appreciable number of cracked tubes from smelt spout openings or boiler floors have boen examined at ORNL in order to characterize the nature of the cracks. An examination generally starts with a dye penetrant test to define the areas on a tube where cracks exist. Samples are selected and cut from the tube, then they are mounted, polished and prepared for microscopic examination. Figure 3 shows a portion of a North American boiler's smelt spout opening that has undergone a dye penetrant examination, while Fig. 4 shows the transgranular cracks that were found in the composite tubing from this spout opening.

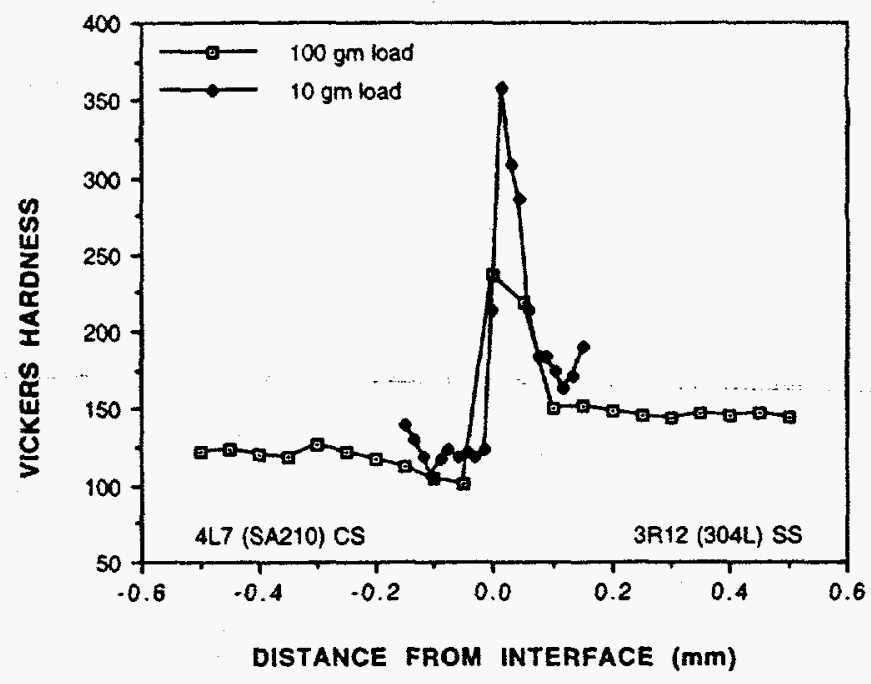

Fig. 2. Vickers hardness versus position in the vicinity of the stainless steel/carbon steel interface in a $304 \mathrm{~L} / \mathrm{SA} 210$ composite tube.

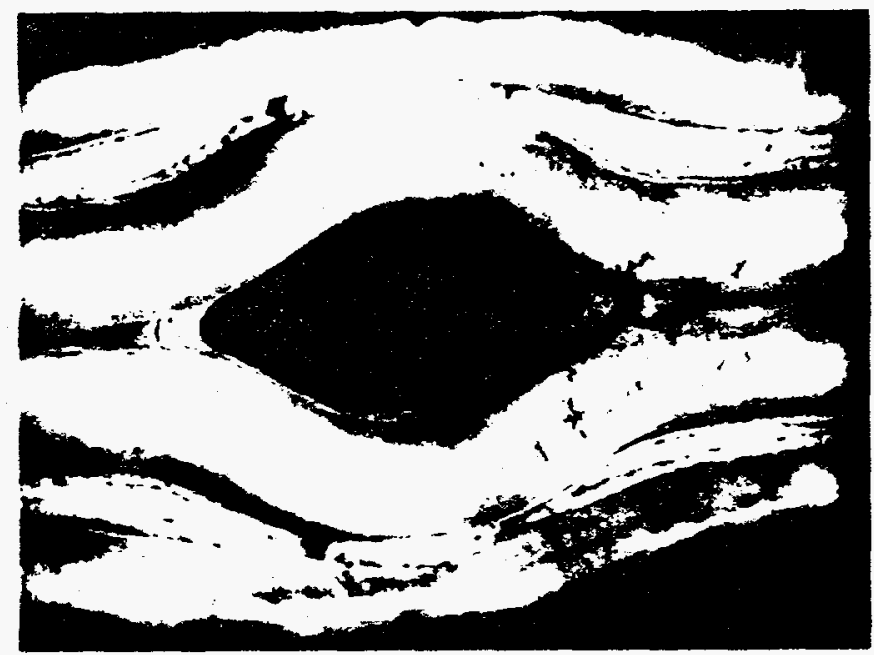

Fig. 3. Wall panel containing a smelt spout opening that has been inspected with dye penetrant to identify the cracked regions.

Many samples from floor tube panels have been examined, and two forms of cracking are generally found. Cracks are either parallel and roughly transverse to the tube axis or appear as an array of interconnecting cracks apparently without a preferred orientation. A floor tube panel from a North American boiler is shown in Fig. 5, and a micrograph showing parallel-type cracks in the composite tubing from this floor is presented in Fig. 6 . In this particular sample, small intergranular cracks were found in the carbon steel immediately beneath a crack along the stainless steel/ carbon steel interface. These cracks appear not to extend more than a few grains into the carbon steel, and certainly do not extend 


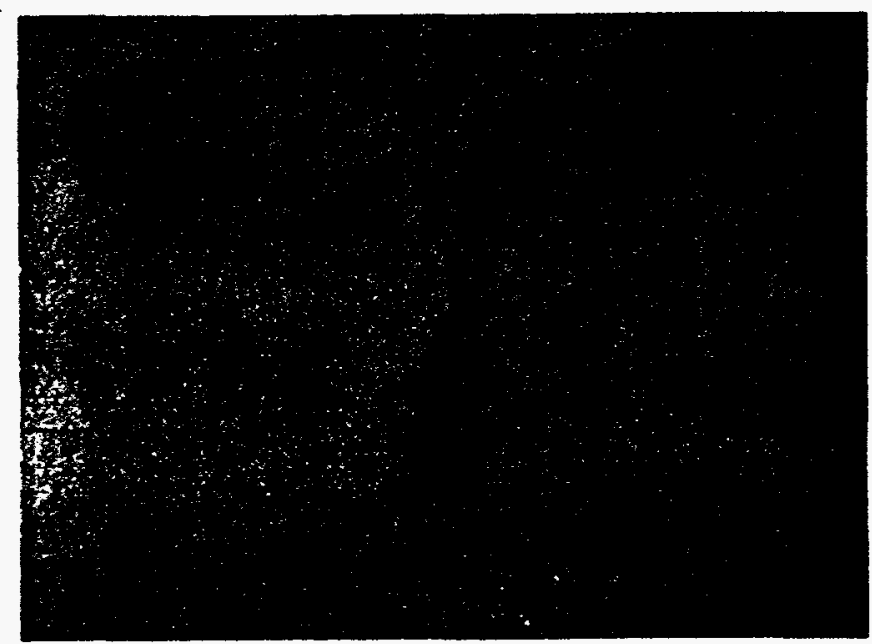

Fig. 4. Cross section of sample from wall panel in Fig. 3 showing transgranular cracking.

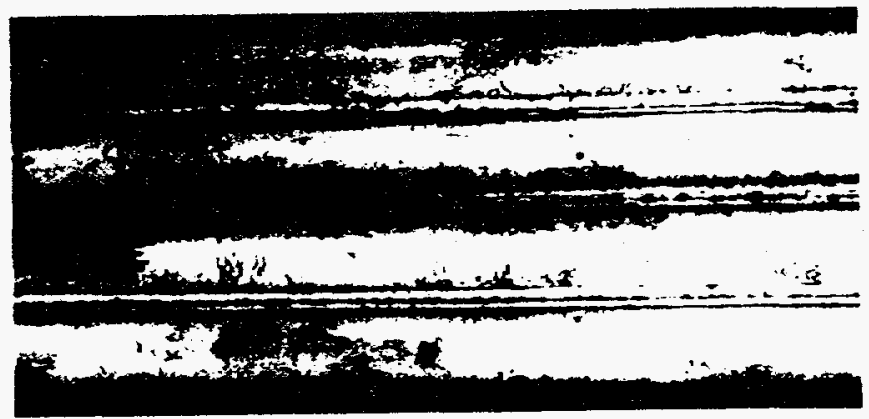

Fig. 5. Floor tube panel from North American boiler showing cracking in composite tubes highlighted by dye penetrant inspection.

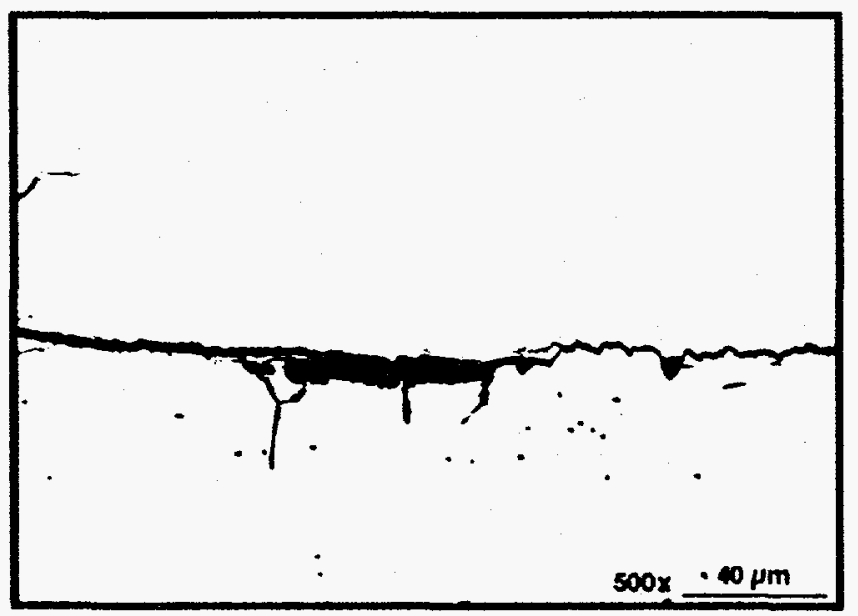

Fig. 6. Micrograph showing cracks in cross section of sample from panel in Fig. 5. Note intergranular attack in the carbon steel.

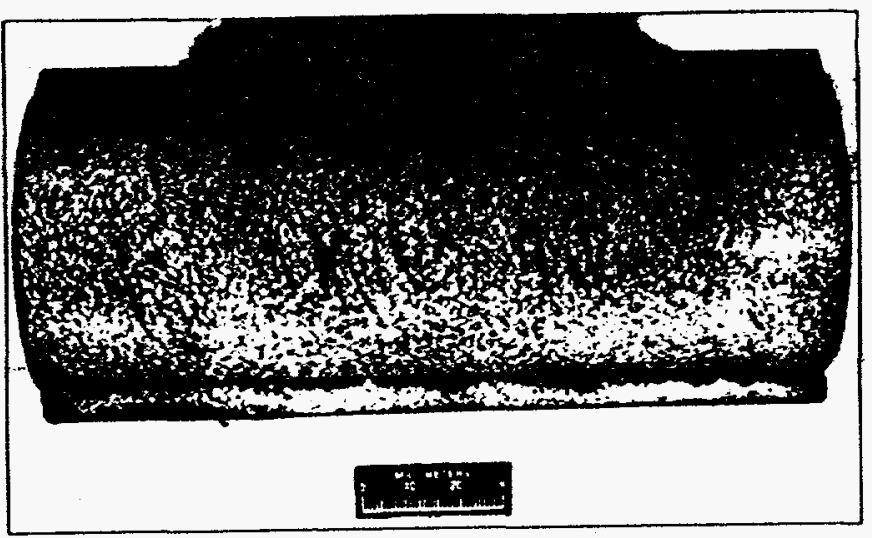

Fig. 7. Floor tube from North American boiler that showed extensive cracking after $1 \frac{1 / 2}{2}$ years service.

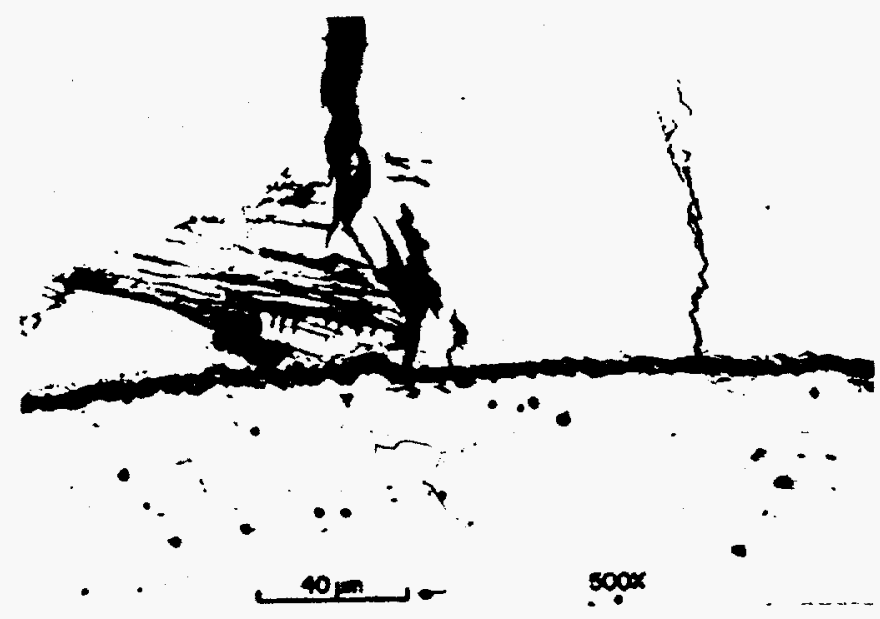

Fig. 8. Micrograph showing cracks in cross section of sample from tube in Fig. 7. Note intergranular attack in the carbon steel.

through the decarburized zone. Cracks in tubes from another North American boiler built by a different manufacturer are shown in Fig. 7. This tube is a second example in which intergranular cracks were found in the carbon steel beneath a crack that runs parallel to the stainless steel/carbon steel interface (see Fig. 8). These are the only two floor tubes received for examination by these authors in which cracking has been found in the carbon steel.

The intergranular cracks in the carbon steel, while not extensions of existing transgranular cracks in the stainless steel, should be viewed with some concern. Apparently another cracking mode, possibly caustic stress corrosion cracking, can be active in the region beneath the cracks that parallel the interface. Chemical 
analyses of the corrosion product in the intergranular cracks showed low levels of sulfur and chlorine and appreciable amounts of oxygen. There is also reason to be concerned about the pitting that is sometimes observed in the carbon steel; an extreme example of pitting, in this case for a smelt spout opening tube from an European mill, is shown in Fig. 9. In this tube, the corrosion pits extend approximately $0.8 \mathrm{~mm}$ into the carbon steel.

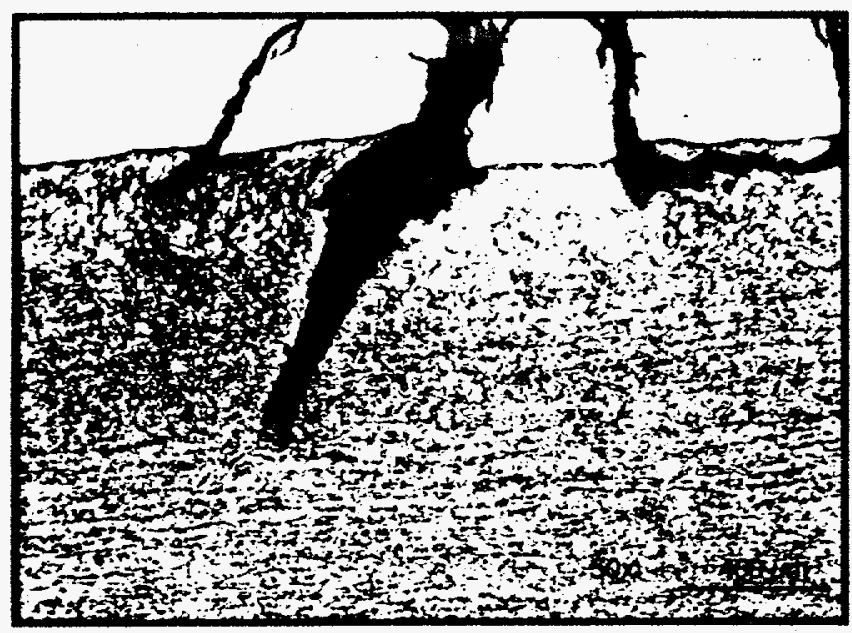

Fig. 9. Micrograph showing severe corrosion pitting in carbon steel of composite tube from Scandinavian boiler.

Based on examination of a large number of cracked composite tube samples, several observations can be made. First, near the outer surface of the stainless steel layer, cracks are generally fairly wide and have little or no branching. Branching is more often found after cracks have proceeded a significant distance into the stainless steel layer. As the cracks approach the stainless steel/carbon steel interface, the cracks either end or turn and proceed in the stainless steel parallel to the interface. Corrosion pits are sometimes found growing into the carbon steel where a crack ends at the interface. Two examples of tubing have been found with intergranular cracks in the carbon steel below a crack that had proceeded along the interface.

Transmission electron microscopy studies. One major issue to be addressed is the mechanism(s) that is(are) responsible for cracking of the stainless steel layer on composite tubes. Morphological differences can sometimes be used to differentiate between fatigue and stress corrosion cracking, but sometimes the available information gives ambiguous indications. Consequently, transmission electron microscopy is being used to look for positive evidence that the composite tube samples have been subjected to cyclic stresses, i.e. fatigue.

Metallic samples that have been subjected to cyclic stresses develop a dislocation structure typified by "cells" along with relatively large and extended stacking faults and fine dislocation loops. Transmission electron microscopy is required to detect these sub-micron sized microstructural features. Utilizing the specialized microanalysis facilities available at ORNL, such a study is underway. Previous TEM studies have been conducted, and those results did not provide strong evidence that isothermal or thermal fatigue had occurred in the samples examined (13). Samples for this previous study were reportedly taken from as near the outer tube surface as possible.

For the current studies, a sample of a fine-grained 304L stainless steel was subjected to about 4,000 mechanical cycles at $300^{\circ} \mathrm{C}$ for use as an isothermal cyclic fatigue reference material. Samples for TEM examination were taken from both the gage section and the shoulder of this sample. Samples were also taken from sections of three different tubes with cracks, including the sample shown in Fig. 7. Two $3 \mathrm{~mm}$ diameter TEM disks were prepared from each of the tubes. One disk was cut from each tube about $0.8 \mathrm{~mm}$ $(0.030 \mathrm{in}$.) below the outer surface of the stainless steel layer, while another sample was taken only $0.13 \mathrm{~mm}(0.005 \mathrm{in}$.) below the outer surface. Such careful sampling was done because microstructure may vary from the outer surface where blunt transgranular cracks were found to the region midway through the stainless layer where a more branched cracking pattern was found.

Currently, the two specimens have been examined from the reference material and the samples taken from near the center of the cladding of the three different tube samples. The samples from the fatigue-control specimen clearly displayed the characteristic cellular dislocation network typical of fatigue. The shoulder sample had a relatively low density of dislocations typical of solution annealed material as shown in Fig. 10. The sample taken from the gage section had a much higher dislocation density with a) cellular network structure containing dislocation dissociation into partial dislocations bounding stacking faults, and b) with dislocation loops (see Fig. 11). Two of the samples taken from the center of the stainless steel layer were from tubes that were put into service much more than ten years ago, and which had many years of exposure. Both of these samples had dislocation structures typical of heavily cold worked $(>20 \%)$ stainless steel. Because of the dense dislocation structures (see Fig. 12 for typical example), any evidence of additional fatigue damage was obscured. The third sample was taken from the center of the stainless steel layer of the tube shown in Fig. 7. This tube was relatively new (boiler operation began in 1993) and had a relatively short (18 months) exposure. As shown in Fig. 13, the dislocation structure of this tube showed much less evidence of cold work and did have some evidence of stacking faults that would be consistent with a small fatigue component to the strain. However, fatigue does not appear to have been a dominant influence on development of the microstructure observed.

Results obtained from these initial sample examinations do not show evidence of a strong influence of fatigue on the microstructures of the samples taken from cracked composite tubes. The samples taken thus far do indicate substantial metallurgical differences in the cladding that are most likely related to processing differences. However, the near surface TEM 


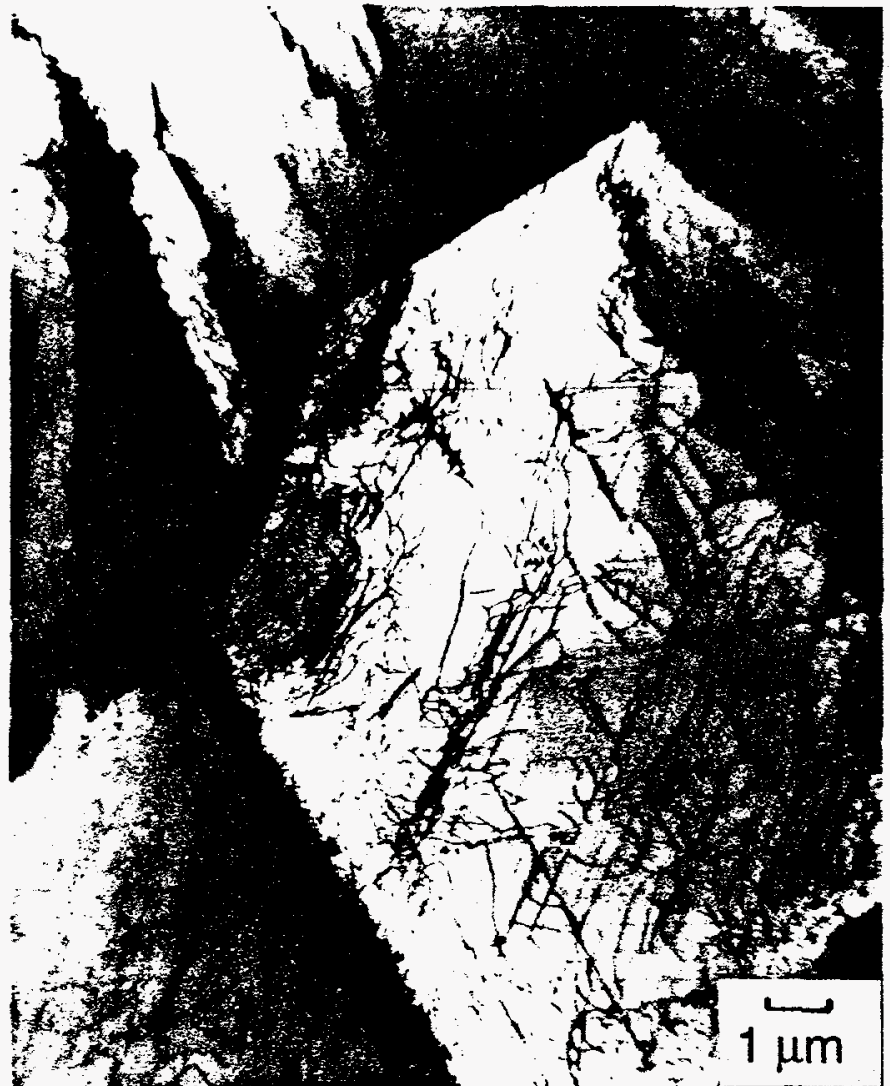

Fig. 10. Microstructure in sample taken from shoulder of a fatigue sample. Note absence of extensive dislocation structure.

samples still need to be examined. Since the crack morphology appears to change in going from the outer surface to the middle of the stainless steel layer, it is important to know whether or not this behavior correlates with differences in the microstructure.

\section{Determination of Floor Tube's Chemical and Thermal} Environment

The Institute of Paper Science and Technology has the lead in collecting data to characterize the environment experienced by composite floor tubes. Although no results are currently available, efforts are underway to collect and analyze samples of smelt and to accumulate data from thermocouples located on recovery boiler floors. One issue that will be addressed is to try to determine whether the smelt immediately adjacent to the floor tubes has a significantly lower melting point than the smelt flowing from the spouts as reported by Ahlstrom (14). This study will also include an effort to confirm that significant temperature fluctuations occur on boiler floor tubes as reported by several observers $(15,16)$.

Fig. 11. (in right hand column) Dislocation structure in sample taken from gage section of a fatigue sample (upper right). Note cellular structure, stacking faults, and loops identified in higher magnification micrograph (lower right).
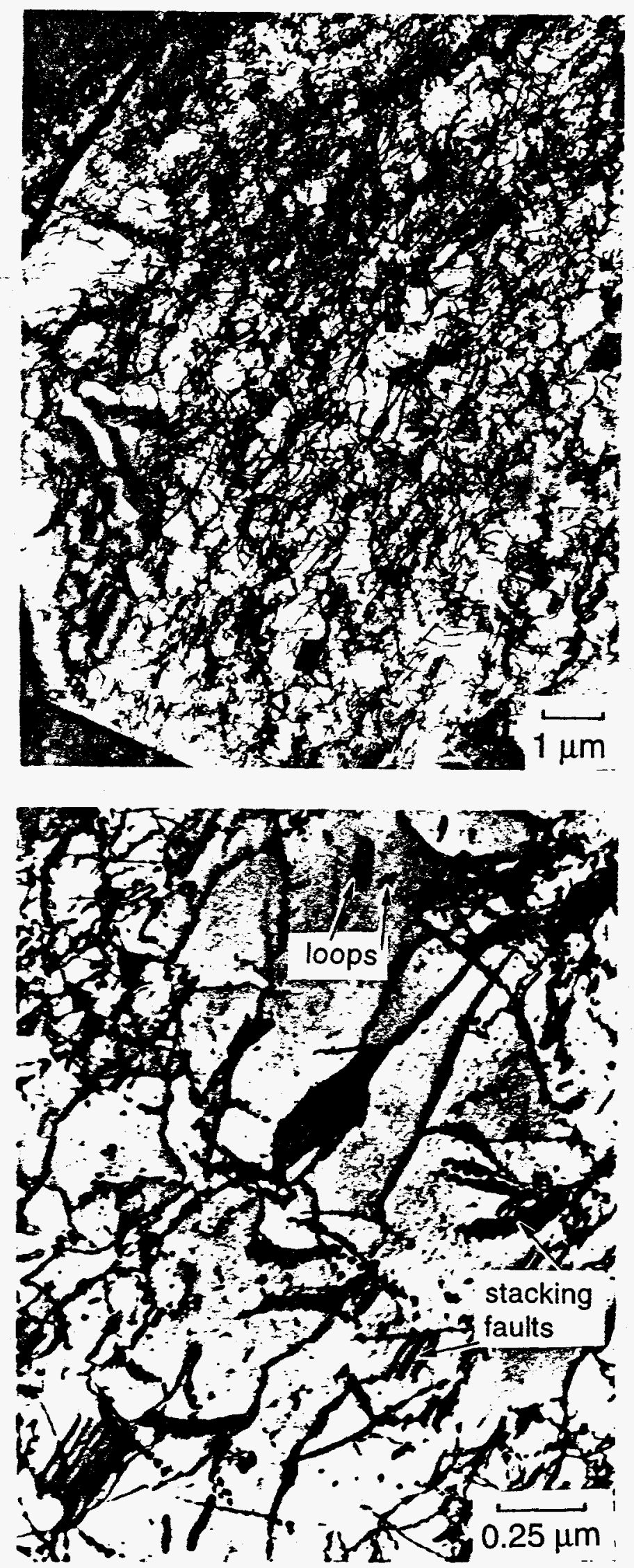


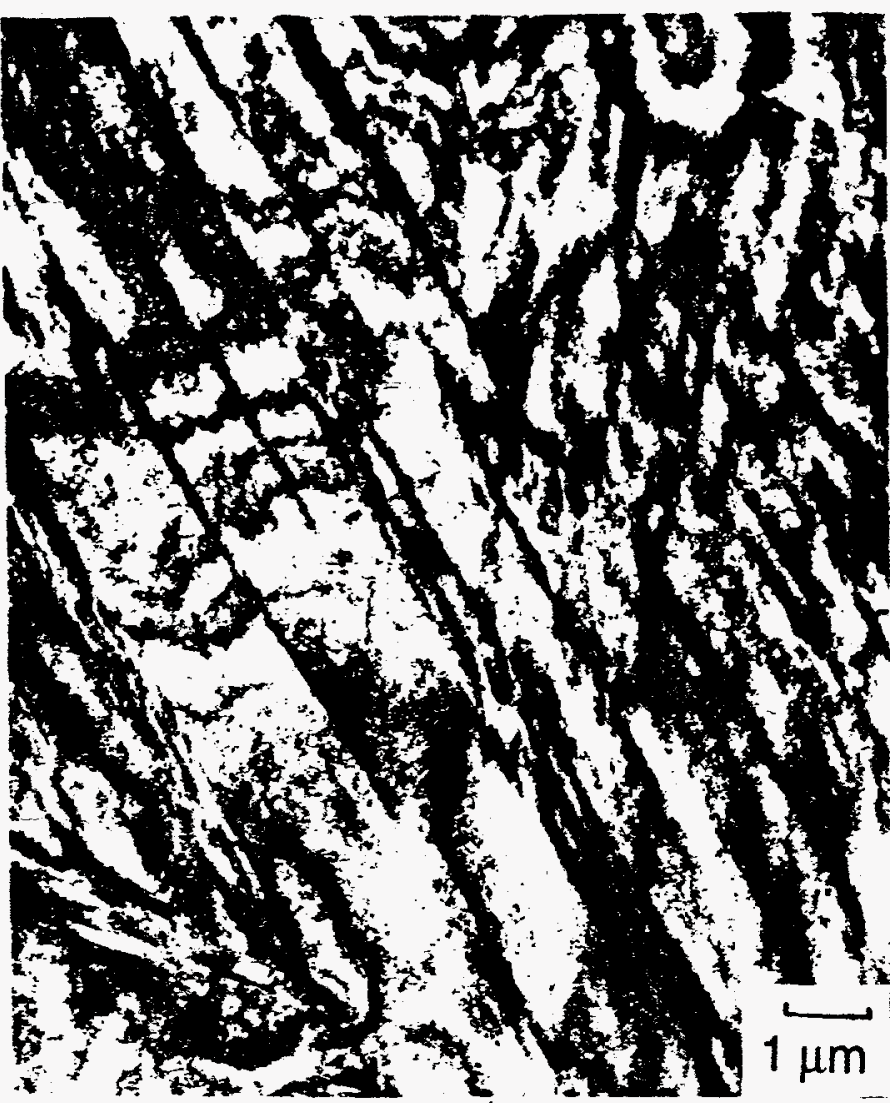

Fig. 12. Dislocation structure in sample taken from cracked tube in smelt spout opening of Scandinavian boiler after extended operation.

\section{Determination of Residual Stresses from Tube Fabrication}

Knowledge of the stress state of the fireside surface of recovery boiler composite tubes is essential in determining the mechanism(s) responsible for cracking of the composite tubes in recovery boiler. If the outer surface of a tube is in tension, then stress corrosion or fatigue mechanisms are possible. On the other hand, if stresses are compressive, then either these mechanisms are not operative or conditions must exist to create tensile stresses in the tubes.

To characterize the residual stresses in composite tubes and panels constructed of composite tubes, a systematic study utilizing neutron and X-ray diffraction methods is being conducted. In the initial studies, the residual stress distribution is being measured in straight composite tubes of various diameters for various clad materials produced by different manufacturers. The stress distribution through the wall of the tubes is measured using neutron diffraction while X-ray diffraction is used to determine the surface stress state. The experimental data obtained for straight composite tubes serve as a baseline for understanding the residual stresses in tube panels and provide input to the modeling task.
The neutron diffraction experiments are performed using the residual stress mapping system at ORNL's High Flux Isotope Reactor which has a very high neutron fluence and is especially appropriate for such studies. Masking slits are positioned before and after the specimen to define a sampling volume, and strain mapping is accomplished using a three-dimensional translation stage mounted on the sample table of the neutron diffractometer $(17,18)$. From the diffraction peaks measured at each location, residual strains are calculated, then residual stresses are calculated from this information using Hooke's law. All strain measurements are made at mid-length of the tube specimens. The tubular materials provided by the Swedish tube manufacturer and $B \& W$ that were used for microstructural characterization were also used for residual stress measurements.

The stress values calculated from the measured strains for $2-1 / 2$ in. OD, 304L/SA210 composite tubes from the two tube manufacturers are shown in Fig. 14. For the tube of Swedish origin, the residual stresses are small in both components, especially in the carbon steel core. The stresses in the stainless steel layer are somewhat larger, but they do not exceed $\pm 150 \mathrm{MPa}$ at maximum. In the stainless steel layer, the axial stress is compressive, but the hoop stress is tensile, although X-ray measurements suggest that the hoop stress also becomes compressive at the surface of the stainless steel layer. The Japanese tube shows a significantly different stress pattern. The stresses in the carbon steel vary over a wider range, and the stresses reach a peak around $200 \mathrm{MPa}$ at the stainless steel/carbon steel interface. At the surface of the stainless stzel, the axial and tangential stresses are compressive.

The difference in the stress distribution between the tubes produced by the two principal manufacturers are likely due to differences in fabrication processing. Evidence supporting this observation is shown in Fig. 15 for measured residual stresses in the Swedish manufacturer's $21 / 2$ and 3 in. OD 825/SA210 tubes. As can be seen, the residual stress patterns in these two tubes are similar and also consistent with surface residual stress data obtained by X-ray measurements. Qualitatively, the stress patterns in the Swedish 825/SA210 tubes are much more similar to the Swedish 304L/SA210 tube [Fig. 14(a)] than to the Japanese 304L/SA2 10 tube [Fig. 14(b)]. It should be noted that while the residual stresses measured at room temperature in a single tube will contribute to the evaluation of the residual stresses at operating conditions, they do not provide sufficient information or justification for selection of the tubing from one manufacturer over that of another manufacturer

Residual stress measurements are continuing and measurements in a welded composite tube panel and in a bent composite tube are scheduled. In addition, because of the interest expressed by many paper companies in using weld overlay tubing to replace composite tubing on recovery boiler floors, the residual stresses in tubing with a $360^{\circ}$ overlay of Alloy 625 are being measured. 


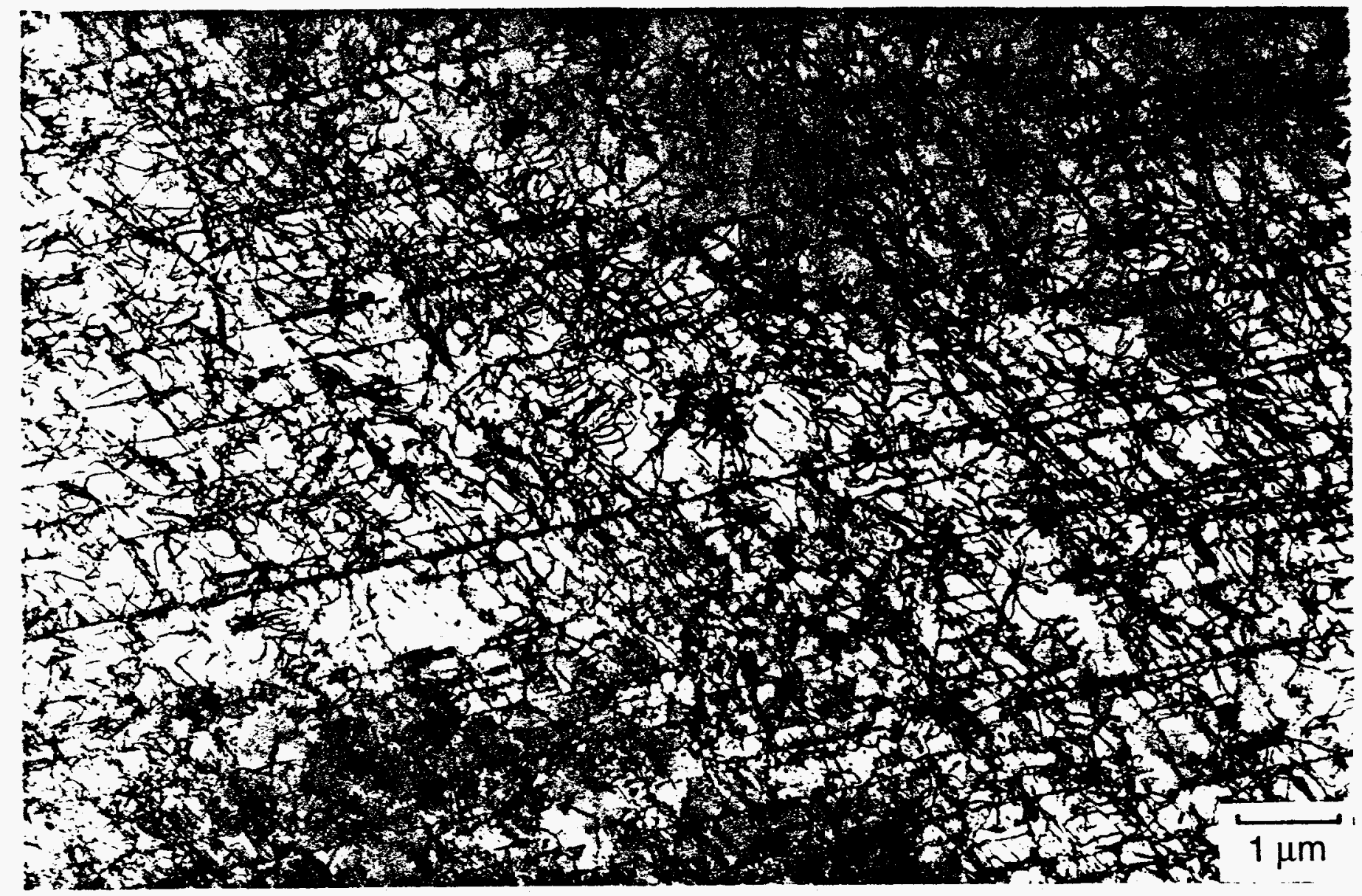

Fig. 13. Dislocation structure in sample taken from cracked floor tube of North American boiler after 18 months of operation.
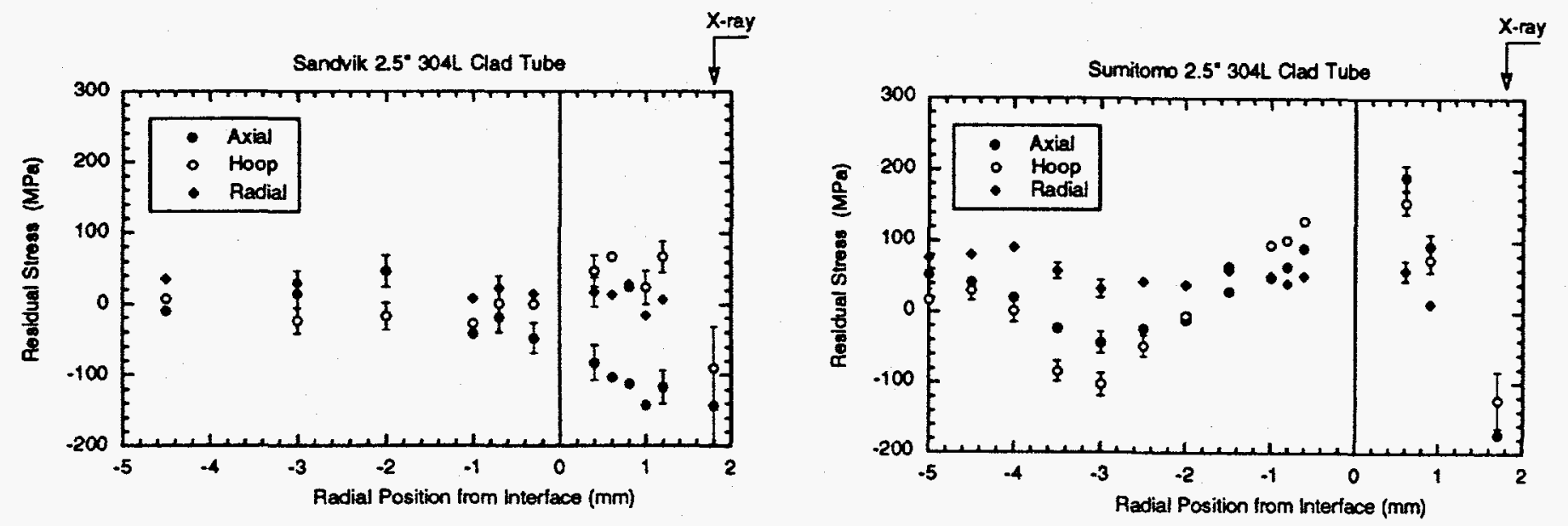

a)

b)

Fig. 14. Residual stresses calculated from strain measurements for a) unexposed Sandvik $2 \frac{1}{2}$ in. OD 3R12/4L7 (304L/SA210) tube and b) unexposed Sumitomo $2 \frac{1}{2}$ in. OD 304L/SA2 10 tube. 

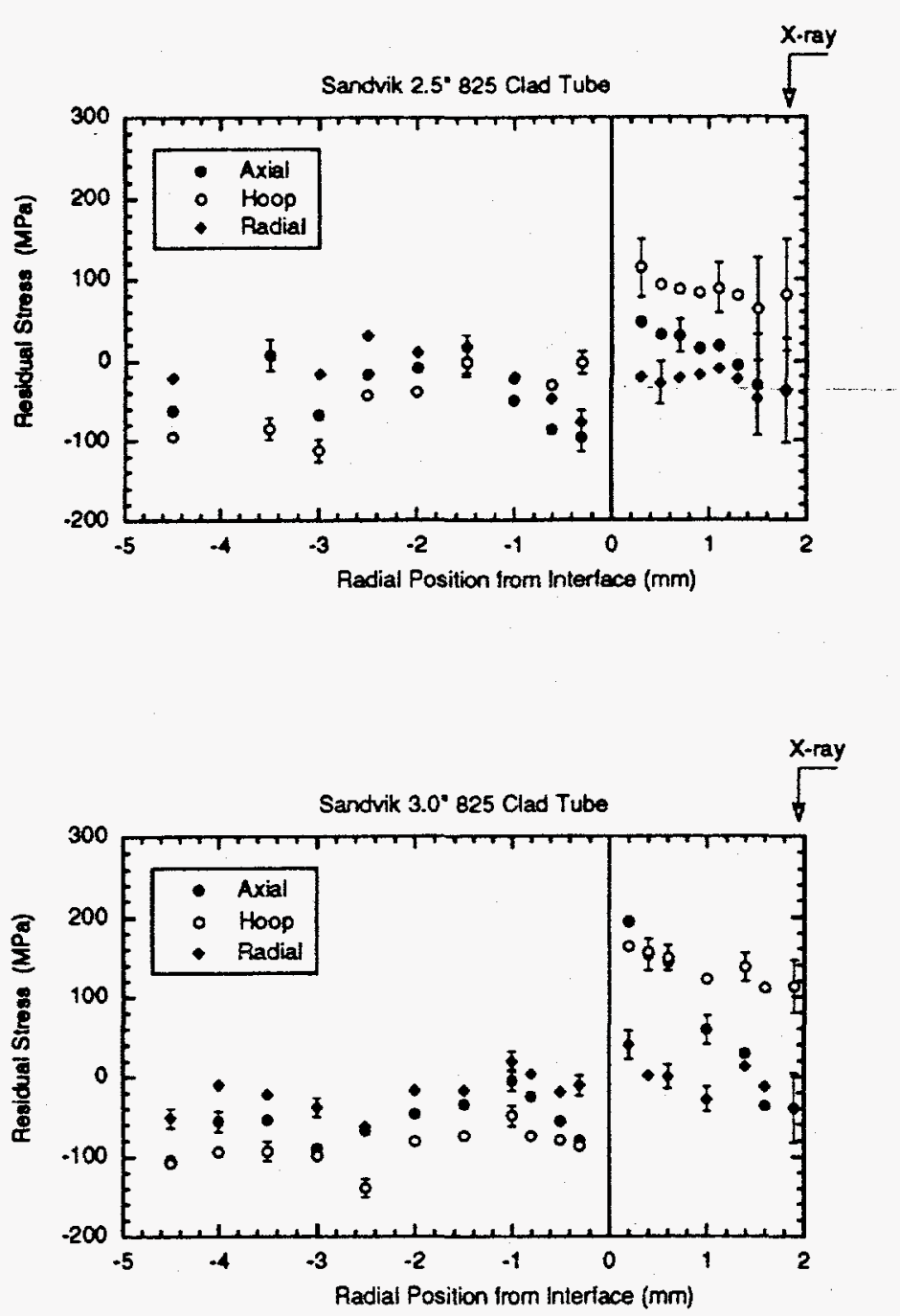

Fig. 15. Residual stresses calculated from strain measurements for unexposed Sandvik SAN $38 / 4 L 7$ with $2 \frac{1}{2}$ and 3 in. ODs.

ORNL-OWG 96M-5117

\section{Composite Tube Model}

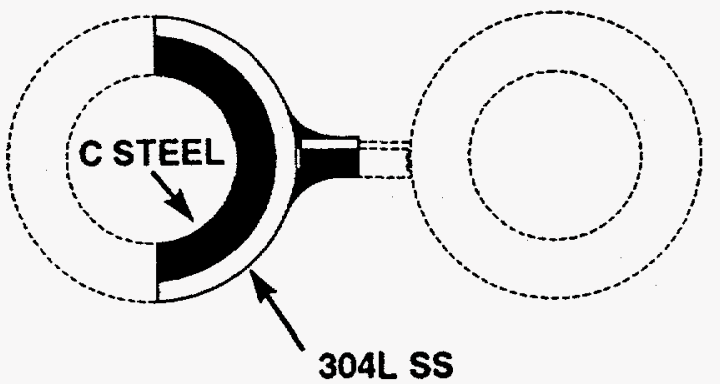

Fig. 16. Configuration used for two-dimensional model of recovery boiler floor panel.

\section{Finite Element Modeling of Stresses in Composite Tubes}

The results of neutron diffraction residual stress measurements provide some of the needed data, but stresses resulting from weld attachment of membranes, internal pressurization of the tubing, and heating on the fireside of the tubes must also be taken into account. To consider these other influences, a two-dimensional model was constructed that assumed the symmetry of a tube panel was such that a tube could be sufficiently represented by a model utilizing one half of the composite tube and one half of the membrane as shown in Fig. 16. The model was first used to take into consideration the effects of membrane weld attachment. This model, when the residual stresses from tube fabrication are taken into consideration, predicts that compressive stresses develop on the stainless steel surface of the composite tube.

When the model is expanded to include internal pressurization of 8.62 $\mathrm{MPa}\left(1250 \mathrm{psi}\right.$ ), heating on the tube fireside to $343^{\circ} \mathrm{C}$, and operation with a tube internal temperature of $287^{\circ} \mathrm{C}$, the axial and tangential stresses on the outer surface of the stainless steel are compressive at all locations for 304L/SA210 tubing from both manufacturers. On the inside surface of the carbon steel tube, stresses are tensile in almost all locations. Assuming the model adequately describes the operating conditions of a composite tube, the compressive axial and tangential stresses on the outer surface of the composite tubing mean that sufficient conditions are not present for stress corrosion cracking or for fatigue.

Observations, by the authors and others, of small areas of high corrosion on studded, carbon steel boiler floors suggest that conditions are not uniform on the floor of a boiler. In fact, results of temperature measurements on boiler floors indicate that thermal fluctuations occur, and these fluctuations are very short-lived and can vary in magnitude from tens of degrees to hundreds of degrees $(15,16)$. To account for this non-uniform behavior, a threedimensional model of a boiler floor was constructed. The model that was eventually used, shown in Fig. 17, assumed a tube panel that was eleven tubes wide and nearly $2 \mathrm{~m}$ long and had two symmetry axes. In order to account for the non-uniform heating that apparently occurs on a boiler floor, a "hot spot" was assumed to exist in the middle of this panel. Two types of hot spots were assumed: one where the entire tube and membrane surface (crownmembrane HS) within a prescribed area was subjected to the extra heating and one where only a portion $\left(120^{\circ}\right)$ of the tube crown (crown HS) was subjected to the extra heating. Without expanding the model to account for the effects of fabrication stresses and membrane weld attachment, calculations show that introduction of either type of hot spot significantly affects the stresses in the tube. As shown in Fig. 18, the tangential stresses developed in a crown hot spot on a 304L/SA2 10 composite tube increase sufficiently that they become tensile. Figure 19 gives a schematic representation of a tube panel showing the deformation of the panel that is caused by a hot spot. The figure also shows (in shades of grey) the stresses on the surface of the tubes resulting from the hot spot. At the time of submission of this paper, several 


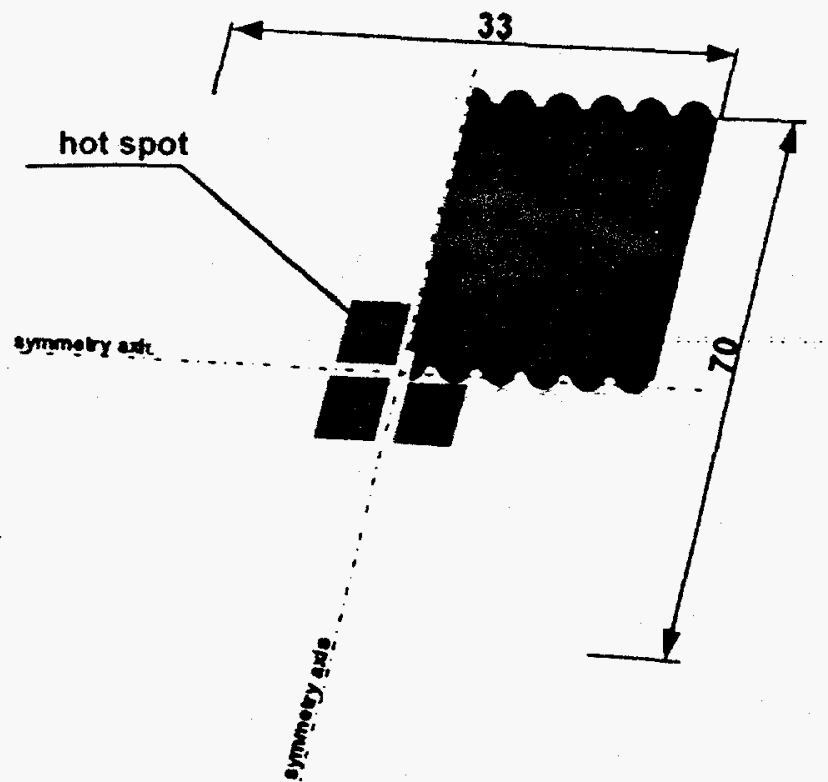

Fig. 17. Configuration used for three-dimensional model of recovery boiler floor panel.

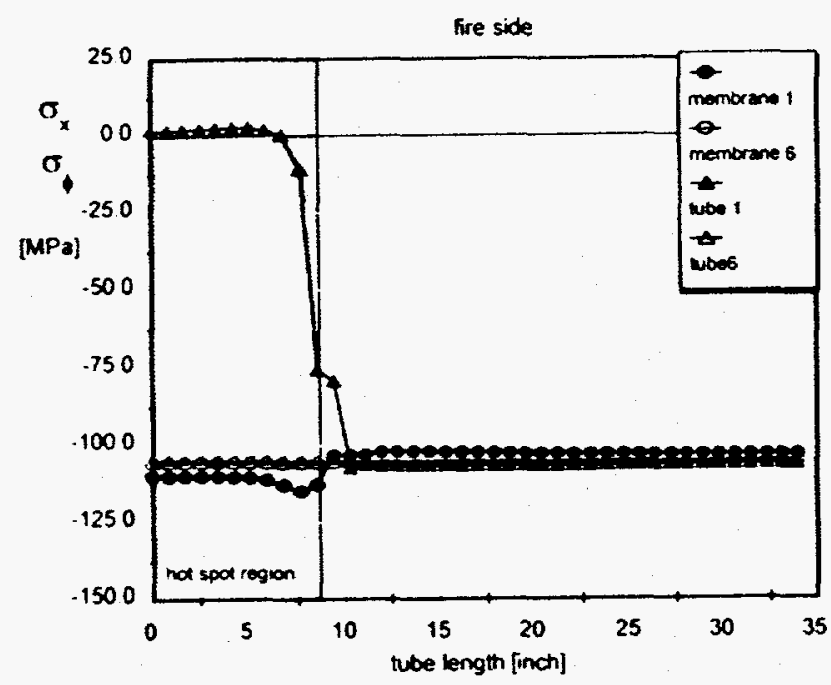

Fig. 18. Tangential stresses developed as the result of a crown hot spot in a 304L/SA210 composite tube panel for a tube and membrane in the hot spot (\#1) and a tube and membrane away from the hot spot (\#6).

refinements need to be made to this model so that the transition from hot spot to normal tube conditions is less abrupt and the other stress sources are considered. Nevertheless, the qualitative results provide a strong indication that the thermal fluctuations or spikes that occur on the boiler floor are probably necessary for tensile stresses to be generated on the fireside of a $304 \mathrm{~L} / \mathrm{SA} 210$ composite tube. Work is continuing to refine this model.

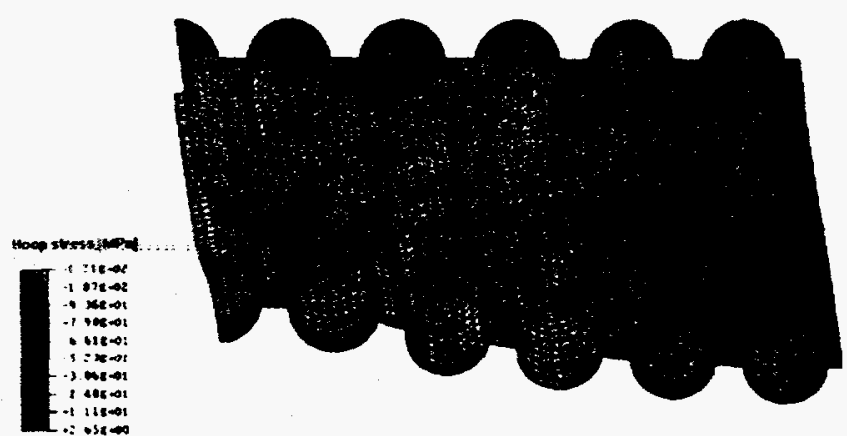

Fig. 19. Graphic display of deformation of a tube panel resulting from a crown hot spot. The gray scale gives an indication of the variation in residual stresses in the tube. The deformation of the panel is exaggerated $100 \times$ to highlight the panel distortion.

\section{SUMMARY}

Cracking has occurred in 304L/SA210 composite tubes in smelt spout openings and recovery boiler floors of many North American mills. The current program is intended to address and to identify altemate materials and/or process changes that could eliminate the cracking problem. Accomplishments to date on this project include review of existing literature and preparation of a summary report, characterization of the microstructure of as-fabricated composite tubing, examination of many samples of cracked tubing, residual stress measurements and finite element modeling of the stress state in composite tubes.

Generally, cracks in composite tubing originate at the outer surface and proceed to some depth in the stainless steel outer layer. Near the outer surface, the cracks are relatively wide, blunt, and unbranched. If the cracks proceed an appreciable distance into the stainless steel, some branching often develops. If the cracks reach the stainless steel/carbon steel interface, the cracks usually end at the interface or turn and proceed in the stainless steel along the interface. Corrosion pits frequently develop in the carbon steel at the end of cracks that terminate at the interface. In a few instances, shallow intergranular cracking has been seen in the carbon steel beneath interfacial cracks in floor tubes.

Transmission electron microscopy studies of material taken from cracked composite tubes have, to this point, concentrated on samples taken from near the center of the stainless steel layer. Two of the samples examined were so heavily cold worked that any microstructural evidence of fatigue would have been obscured by the cold worked structure. On one sample of a newer composite tube, there were a few indications of fatigue, but the evidence did not indicate that fatigue had played a major role in developing the dislocation structure in the sample. 
Neutron and X-ray diffraction have been used to measure the residual stresses developed during fabrication of composite tubes from both major tube fabricators. Differences in the stress distribution indicate there are probably significant differences in the fabrication methods used by the two manufacturers.

Finite element modeling to determine the stresses under operating conditions predicts compressive axial and tangential stresses on the fireside surface of $304 \mathrm{~L} / \mathrm{SA} 210$ composite tubes from both major manufacturers. Initial results from a three-dimensional model of a composite tube panel indicate that tensile tangential stresses would develop if a hot spot occurs on the crown of the tubes in a limited area.

The information accumulated in this study is not yet sufficient to identify the mechanism(s) responsible for the cracking. However, the thermal fluctuations that are reported to occur on the floor tubes probably result from molten smelt reaching or approaching the surface of the tubes and these fluctuations likely create conditions where tensile stresses develop on the fireside surface of the composite tubes. As a result of these stresses being developed, thermal fatigue, corrosion fatigue, and stress corrosion cracking become plausible mechanisms for cracking of composite tubes in black liquor recovery boilers.

\section{ACKNOWLEDGMENTS}

The authors wish to acknowledge the efforts of H. F. Longmire for preparation of metallographic specimens, J. W. Jones for preparation of TEM samples, D. F. Wilson, S. J. Pawel, and J. R. DiStefano for review of the document, and Sandvik Steel for contribution of considerable tube material. Information, tube samples, and assistance have also been provided by ABB-CE Services, Inc., A. Ahlstrom Corporation, Babcock \& Wilcox, Kvaerner Pulping Technologies, Tampella Power Corporation, $\mathrm{AF}$-Industrins Processkonsult $\mathrm{AB}, \mathrm{Bacon}$ Donaldson Consulting Engineers, Champion International Corporation, Georgia-Pacific, P. H. Glatfelter, International Paper, MacMillan Bloedel Inc., Parsons \& Whittemore Engineering Co., Inc., Union Camp Corporation, Westvaco, Weyerhaeuser, and Weyerhaeuser Canada.

\section{REFERENCES}

1. Odelstam, T., "Performance of Composite Furnace Tubes in Recovery Boilers," in Pulp and Paper Industry Corrosion Problems, Volume 4, Swedish Corrosion Institute, Stockholm, 1983, page 64.

2. Wensley, D.A., "Corrosion and Cracking of Composite Boiler Tubes," 1986 Kraft Recovery Operations Seminar, TAPPI, Atlanta, 1986, p. 231.

3. Task Group T-SH-1, (Fireside Corrosion in Kraft Recovery
Boilers), Minutes, National Association of Corrosion Engineers, Houston, Sept. 24, 1986.

4. Singbeil, D.L. and Gamer, A., Tappi J., "Lower Fumace Corrosion in Kraft Recovery Boilers, Part 1," 72 (6), 136 (1989).

5. Task Group T-5H-1, (Fireside Corrosion in Kraft Recovery Boilers), Minutes, National Association of Corrosion Engineers, Houston, Sept. 16, 1992.

6. Task Group T-5H-1, (Fireside Corrosion in Kraft Recovery Boilers), Minutes, National Association of Corrosion Engineers, Houston, Mar. 11, 1993.

7. Klarin, A., Tappi J., "Floor Tube Corrosion in Recovery Boilers," 76 (12): 183 (1993).

8. Karjalainen, L.P., Proceedings of the Seventh International Symposium on Corrosion in the Pulp and Paper Industry, "Cracking Failures in Composite Tubes in Kraft Recovery Boilers," p. 243 (1992).

9. Eilersson, T. and Leijonberg, A., Proceedings of the Seventh International Symposium on Corrosion in the Pulp and Paper Industry, "Recovery Boiler Furnace Floor - Smelt Side Damages," p. 259 (1992).

10. Makipaa, M., Salonen, J., Ehrnsten, U., and Sarmola, O., Proceedings of the Seventh International Symposium on Corrosion in the Pulp and Paper Industry, "Case Studies on Corrosion and Material Problems in Black Liquor Recovery Boilers," p. 277 (1992).

11. Hanninen, $\mathrm{H}, 30$ Years Recovery Boiler Co-operation in Finland, "Cracking and Corrosion Problems in Black Liquor Recovery Boilers," Finnish Recovery Boiler Committee, Helsinki, 1994, p. 121.

12. Sugimura, Y., Lim, P.G., Shih, C.F., and Suresh, S., Acta metall. mater., "Fracture Normal to a Bimaterial Interface: Effects of Plasticity on Crack-Tip Shielding and Amplification," 43 (3): 1157 (1995).

13. Makipaa, M., Nenonen, P., Salonen, J., and Hakkarainen, T., Proceedings of the Eighth International Symposium on Corrosion in the Pulp and Paper Industry, "Studies with TEM, SEM and Optical Microscope on the Cracking of BLRB Composite Floor Tubes," p. 189 (1995).

14. Private communication, L. Koivisto and E. Kiiskila, A. Ahlstrom Corporation to J. P. Gorog, Weyerhaeuser, D.L. Singbeil, Pulp and Paper Research Institute of Canada, and J.R. Keiser, Oak Ridge National Laboratory. 
15. Private communication, M.P. LeBel, ABB CE Services to J. R. Keiser, Oak Ridge National Laboratory.

16. Private communication, D.C. Crowe, Union Camp Corporation to J.R. Keiser, Oak Ridge National Laboratory.

17. Root, J.H., Holden, T.M., Schroder, J., Hubbard, C.R., Spooner, S., Dodson, T.A., and David, S.A., Matl. Sci. Tech., "Residual Stress Mapping in Multipass Ferritic Steel Weld," 9 (9): 754 (1993)

18. Wang, X.-L., Hubbard, C.R., Spooner, S., David, S.A., Rabin, B.H., and Williamson, R.L., Mat. Sci. Eng., "Mapping of the Residual Stress Distribution in a Brazed Zirconia-Iron Joint (in press). 